\title{
Evaluation of Pathogenicity of Candida albicans in Germina- tion- ready States Using a Silkworm Infection Model
}

\author{
Haruhito Matsumoto ${ }^{1}$, Jun-ichi Nagao ${ }^{1}$, Tamaki Cho ${ }^{1}$, Jun Kodama ${ }^{2}$ \\ ${ }^{1}$ Department of Functional Bioscience, Fukuoka Dental College, Fukuoka, Japan \\ ${ }^{2}$ Department of Morphological Biology, Fukuoka Dental College, Fukuoka, Japan
}

\begin{abstract}
We previously developed an $\mathrm{N}$-acetyl-D-glucosamine (GlcNAc) medium which induces Candida albicans to undergo a yeast-to-hyphal transition through a cAMP-PKA pathway. Microarray analysis demonstrated that 18 genes, including ALS3 that encodes a cell wall adhesion, were upregulated by 30 min incubation of yeast cells at $37^{\circ} \mathrm{C}$ in the GlcNAc medium. To investigate the differences between morphological transition and morphotype in $C$. albicans as a consequence of infection, this study utilized a silkworm infection model as an invertebrate mini-host. We prepared 3 different conditions of $C$. albicans cells in vitro by changing the incubation times in the GlcNAc medium: yeast-form cells at 0 min (Y0 cells), yeast-form cells in germination-ready state at $60 \mathrm{~min}$ (Y60 cells), and hyphal cells at $120 \mathrm{~min}$ (H120 cells), and compared their pathogenicities. We performed the infection study at various temperatures to find temperature-dependent virulence factors in vivo. Y60 cells in germination-ready state in the GlcNAc medium showed higher pathogenicity in vivo compared to $\mathrm{YO}$ and $\mathrm{H} 120$ cells at $30^{\circ} \mathrm{C}$. Y60 cells proliferated in silkworms $24 \mathrm{~h}$ post-injection at $30^{\circ} \mathrm{C}$, whereas the other 2 cell types did not. In vitro analysis demonstrated that $\mathrm{Y} 60$ cells, but not $\mathrm{Y} 0$ cells, germinated in the silkworm hemolymph at $30^{\circ} \mathrm{C}$. However, $\mathrm{Y} 0$ and $\mathrm{Y} 60$ cells showed a similar degree of germination in the silkworm hemolymph at $37^{\circ} \mathrm{C}$, although no significant difference in silkworm survival after infection with each cell type was observed at $37^{\circ} \mathrm{C}$. These results suggested that the germination-ready state induced by the GlcNAc medium contributed to virulence in the silkworm.
\end{abstract}

Key words : Candida albicans, morphogenesis, morphotype, $N$-acetyl-D-glucosamine, pathogenicity, virulence factor, silkworm

\section{Introduction}

Candida albicans is a human commensal colonizer of mucosal tissues (i.e., oral, vaginal, and gastrointestinal) and skin. C. albicans can become pathogenic, often causing an opportunistic infection in individuals with immune defects, such as oral candidiasis and vaginal candidiasis. The predominance of this fungus in the gastrointestinal tract often leads to a systemic dissemination. The increase in the number of reports on the emergence of resistance strains against frontline antifungal agents is currently considered as a potential health issue ${ }^{1)}$. Therefore, identification of virulence factors that can be targeted by novel antifungal agents is warranted.

To understand the virulence mechanism of $C$. albicans, a number of invertebrate mini-host systems using Drosophila melanogaster ${ }^{2.37}$, Caenorhabditis elegans ${ }^{4,5)}$, and Galleria mellone$1 / a^{6-8)}$ have been developed. These invertebrate models offer a number of advantages over mammalian vertebrate models because of their small size and minimal associated ethical issues, and thus these models are considered useful in investigating $C$. albicans pathogenicity in mucosal infections ${ }^{9}{ }^{10)}$. C. albicans undergoes a morphological transition from yeast to hyphal form in response to various environmental stimuli, includ-

Address for correspondence : Tamaki Cho

Department of Functional Bioscience, Fukuoka Dental College Fukuoka

Received : 3, December 2012, Accepted : 26, December 2012 
ing temperature, $\mathrm{pH}$, and nutrients. Some theories suggest that the loss of morphological switching is accompanied by a diminished virulence ${ }^{11-13)}$. Some studies using invertebrate mini-host systems commonly focused on the morphological switching of $C$. albicans. Fuchs et al. ${ }^{14)}$ recently evaluated the roles of genes involved in hyphal morphogenesis in $C$. albicans pathogenicity using the $\mathrm{G}$. mellonella model maintained at $37^{\circ} \mathrm{C}$. They demonstrated that filamentation is important, but not sufficient to kill G. mellonella and that other virulence factors may be associated with genes that regulate filamentation. Earliev, Hamamoto et al. ${ }^{15)}$ developed a silkworm model for $C$. albicans infection to evaluate the effectiveness of antifungal agents and obtained results equivalent to those using a mouse model. Hanaoka et al. ${ }^{16)}$ also used a silkworm model to evaluate the role of the protein phosphatase gene in $C$. albicans pathogenicity. Interestingly, all pathogenicity studies using silkworm infection models were performed specifically at $27^{\circ} \mathrm{C}$.

In this study, we evaluated the consequence of morphological transition and morphotype in $C$. albicans infections using the silkworm infection model. Several reports indicated that the positional effects of URA3 influenced the phenotypes of morphological switching and virulence in $C$ albicans mutants ${ }^{17-20)}$. In addition, it has also been recently shown that genetic manipulation of $C$. albicans can lead to aneuploidy, which in turn may occasionally influence the degree of virulence ${ }^{21)}$. Therefore, the results obtained from these molecular biotechnological analyses could potentially lead to incorrect interpretations of the potential contributions of specific genes in pathogenesis. To reduce problems related to genetic manipulation of the $C$. albicans genome, we developed a strategy that does not require the use of genetic manipulation. We previously developed a hyphal-inducing $\mathrm{N}$-acetyl-D-glucosamine (GlcNAc) medium ${ }^{22)}$, in which 3 different cell stages of $C$. albicans were prepared by altering the incubation times at $37^{\circ} \mathrm{C}$ : yeast-form cells at 0 min, yeast-form cells in germination-ready state at $60 \mathrm{~min}$, and hyphal cells at $120 \mathrm{~min}$. Morphological events in $C$. albicans maintained in vitro are strongly influenced by temperature. The capability of maintaining silkworms at various temperatures serves as an advantage for this invertebrate animal model, allowing us to evaluate temperature-dependent pathogenicities in $C$. albi- cans.

\section{Materials and Methods}

\section{Strain and growth conditions}

C. albicans strain SC5314 was maintained as frozen glycerol stocks at $-80^{\circ} \mathrm{C}$ before streaking on YPD (1\% yeast extract, $2 \%$ Bacto-peptone, and $2 \%$ glucose) agar medium at $37^{\circ} \mathrm{C}$. Germ tubes were induced in a GlcNAc medium (L-thiazolidine4-carboxylic acid, L-proline, sodium bicarbonate, sodium phosphate monobasic, sodium acetate, and $\mathrm{N}$-acetyl-D-glucosamine, $\mathrm{pH} 6.65$ ) according to the method described by Cho et al. ${ }^{22)}$. The logarithmic phase cells $\left(10^{6} \mathrm{cells} / \mathrm{ml}\right)$ cultured in YPD medium at $37^{\circ} \mathrm{C}$ with constant agitation were treated with $20 \mathrm{mM}$ hydroxyurea (HU; Wako) for 1 cell cycle to synchronize the cell cycle. HUtreated cells were then inoculated into the GlcNAc medium at a final concentration of $1 \times 10^{5}$ cells $/ \mathrm{ml}$ and maintained at $37^{\circ} \mathrm{C}$. The GlcNAc medium promoted the transition from yeast to hyphae without cellular growth after incubation for $60 \mathrm{~min}$, reaching around $100 \%$ transition at 120 min. Cells were collected at 0 min (cells in yeast form), 60 min (cells in yeast form but ready to germinate and enter hyphal growth), and $120 \mathrm{~min}$ (cells in a hyphal form), and washed with phosphate buffer. The hyphal cells incubated in the GlcNAc medium for over 120 min aggregated during sample preparation.

\section{Silkworm infection experiments}

Silkworms were infected with C. albicans following the protocol of Hamamoto et al. ${ }^{15)}$ Fifth instar larvae of the 0211 silkworm strain were provided by the Institute of Genetic Resources Faculty of Agriculture, Kyushu University, which is a participant in the National Bio-Resource Project of the MEXT, Japan. On the first day, the larvae were fed for the entire day with an adequate amount of mulberry leaves at room temperature $\left(25^{\circ} \mathrm{C}\right)$, those reaching an approximate body weight of $1.2 \mathrm{~g}$ were collected the next day. C. albicans cells (50 $\mu \mathrm{L}$ ) were injected into the hemolymph through the dorsal surface using a 26-gauge needle (1-3 $\times$ $10^{4}-10^{6}$ cells/g-silkworm). After injection, the silkworms were placed at $20^{\circ} \mathrm{C}, 30^{\circ} \mathrm{C}$, and $37^{\circ} \mathrm{C}$ without food and their survival monitored at 10, 21, 24, 32, 48, $58 \mathrm{~h}$ post-injection. More than 15 silkworms were used for each condition, with the experiments replicated, making a total of more than 30 
silkworms.

The morphology of $C$. albicans these are known to thrive within their hosts and was abserved by injecting silkworms $(n=3)$ with the fungus $\left(10^{5}\right.$ cells/g-silkworm), incubating at $30^{\circ} \mathrm{C}$ for $24 \mathrm{~h}$, fixing in $15 \%$ formalin neutral buffer solution (Sigma), and embedding in paraffin. Sections were transversely cut and stained with periodic acid Schiff (PAS). To count the number of $C$. albicans cells in silkworms $24 \mathrm{~h}$ after injecting $10^{5}$ cells/g silkworm at $30^{\circ} \mathrm{C}$, the silkworms $(n=5)$ were wiped with swabs, homogenized, and diluted with phosphate buffer. The samples were then plated on a YPD agar medium, incubated at $37^{\circ} \mathrm{C}$ for $24 \mathrm{~h}$, and colonies emerging on the plate were counted.

\section{Morphogenesis of $\boldsymbol{C}$. albicans in hemolymph in vitro}

Hemolymph was collected from larvae by cutting off the rear legs according to the method described by Kaito et al. ${ }^{23)}$. The hemolymph was diluted with insect physiological saline (IPS) buffer (150 mM sodium chloride, $5 \mathrm{mM}$ potassium chloride, $10 \mathrm{mM}$ Tris- $\mathrm{HCl} \mathrm{pH} \mathrm{6.9,} 10 \mathrm{mM}$ EDTA, and $30 \mathrm{mM}$ sodium citrate). The suspension was centrifuged at $700 \times \mathrm{g}$ for $5 \mathrm{~min}$ at $4^{\circ} \mathrm{C}$ to remove insect-cell components such as hemocytes. The supernatant was then passed through a $0.45-\mu \mathrm{m}$ filter and retained as germ-free hemolymph. C. albicans cells were inoculated in $10 \%$ germ-free hemolymph in IPS for $2 \mathrm{~h}$ at $30^{\circ} \mathrm{C}$ or $37^{\circ} \mathrm{C}$. The morphology of $C$. albicans was examined under a microscope, and the percentage of hyphal cells was determined by screening approximately 200 C. albicans cells.

\section{Microarray analysis}

Microarray analysis was conducted according to the method described by Cho et al. ${ }^{24)}$. Briefly, $C$. albicans strain JCM9061 cells at logarithmic phase were adjusted to $3 \times 10^{4}$ cells $/ \mathrm{mL}$ and incubated in the GlcNAc medium at $37^{\circ} \mathrm{C}$ for $30 \mathrm{~min}$. In this condition, the cells underwent a morphological transition from yeast to hyphae as efficiently as that observed in C. albicans strain SC5314. Total RNA was extracted from the cells and microarray analysis was performed. Experiments were replicated, with the quality of the arrays examined during each assay. Genes that were shown to be upregulated by more than 2-fold relative to that of logarithmic phase cells were selected. Replicate experiments showed correlation coefficients of $>$ 0.9979 .

\section{Statistical analysis}

Data are shown as means \pm standard deviations obtained from at least 2 independent experiments. Statistical differences between groups presented in Fig. 2 were evaluated using a twotailed student's $t$ test. A $P$ value of $<0.05$ was considered significant.

\section{Results}

\section{GlcNAc medium induced morphological transitions in \\ C. albicans}

We previously developed a GlcNAc medium that can induce $C$. albicans to morphologically transform from yeast to hyphae at $37^{\circ} \mathrm{C}^{22}$. In this medium, germ tubes started to emerge after 60 min, and almost $100 \%$ of the cells possessed germ tubes at 120 min of culture (Figs. 1A and 1B). We also confirmed by counting colony-forming units (CFU) that no yeast-form cells were growing in this medium (data not shown).

Cho et al. ${ }^{24)}$ previously reported that the intracellular cAMP level of $C$. albicans increased after 180 min of incubation in the GlcNAc medium. We performed DNA microarray analysis to identify the genes affected by incubating $C$. albicans in this medium. Eighteen genes showing at least a two-fold upregulation after incubation in the GlcNAc medium for $30 \mathrm{~min}$ are listed in Table 1. These genes have been associated with GlcNAc catabolism, amino acid biosynthesis/permease, carbon metabolism including gluconeogenesis, glyoxylate cycle, and $\beta$-oxidation. In addition, the genes ALS3, which encodes an adhesin and is a cyclic AMP protein kinase A (CAMP-PKA) pathway dependent; FRP1, which encodes ferric reductase; HSP12, which encodes a heat-shock protein; and $D Q D 1$, which encodes a putative 3dehydroquinate dehydratase, were found to be upregulated. Several genes downregulated at least two-fold were also observed, with the majority of these genes involved in protein synthesis (data not shown).

\section{Effect of C. albicans morphotype on silkworm mortality}

To examine whether the morphotype of $C$. albicans influenced the pathogenicity in silkworms, we prepared 3 types of $C$. albicans cells by changing their incubation time in the GlcNAc medium, namely $0 \mathrm{~min}, 60 \mathrm{~min}$, and $120 \mathrm{~min}$ for the generation of $\mathrm{YO}, \mathrm{Y} 60$, and $\mathrm{H} 120$ cells, respectively (Fig 1B). 


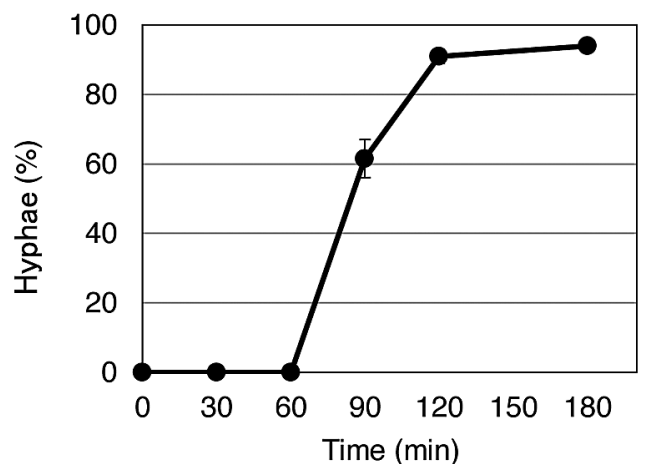

(a)

$0 \mathrm{~min}$

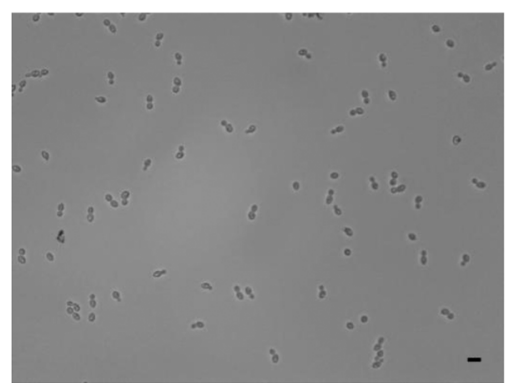

$60 \mathrm{~min}$

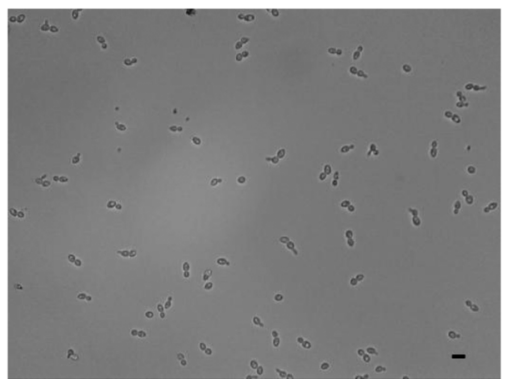

(b)
$120 \mathrm{~min}$

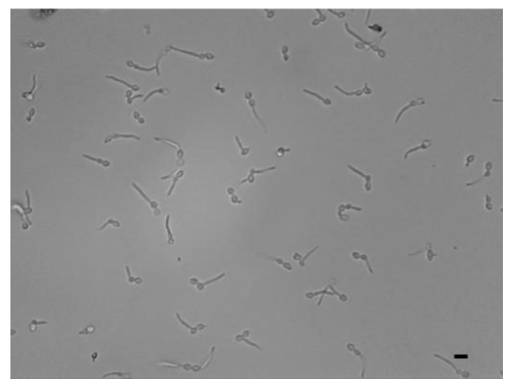

Fig. 1. C. albicans transition from yeast to hyphal form in the GlcNAc medium. C. albicans at logarithmic phase $\left(10^{5} \mathrm{cells} / \mathrm{ml}\right)$ was inoculated in the GlcNAc medium and incubated at $37^{\circ} \mathrm{C}$. (A) Time-dependent transition of $C$. albicans from yeast to hyphae. The percentage of germ tube formation at various time points was determined through microscopic examination of at least 100 cells. (B) Morphology of $C$. albicans at various incubation times in the GlcNAc medium. Bar represents $10 \mu \mathrm{m}$.

In order to examine whether C. albicansinduced silkworm mortality follows a dosedependent manner, larvae were injected with $10^{6}$, $10^{5}$, and $10^{4} \mathrm{C}$. albicans $Y 0$ cells and their mortality at $30^{\circ} \mathrm{C}$ was recorded. As shown in Fig. $2 \mathrm{~A}$, over $60 \%$ of the larvae injected with $C$. albicans $\left(1 \times 10^{6}\right.$ cells) were killed within $24 \mathrm{~h}$ and $100 \%$ within $40 \mathrm{~h}$. Larvae injected with $10^{5}$ cells showed $100 \%$ survival at $24 \mathrm{~h}$, whereas a $50 \%$ larvae mortality was observed within $45 \mathrm{~h}$. Over $70 \%$ of the larvae injected with $10^{4}$ cells were alive even at $50 \mathrm{~h}$ postinjection. As shown in Fig. 2B, the larvae infected with $C$. albicans turned black in color, possibly because of the melanization process described by Hamamoto et al. ${ }^{15)}$. In contrast, all of the larvae injected with heat-inactivated cells $\left(10^{6}\right.$ cells) or phosphate buffer survived $58 \mathrm{~h}$ post-injection (Fig. 2A). These results indicated that whole, living cells of $C$. albicans killed silkworms in a dosedependent manner, which corresponds to the results of Hanaoka et al. ${ }^{16)}$. Examination of the morphology of $C$. albicans in the larval tissues also showed that $24 \mathrm{~h}$ after inoculation of $10^{5}$ cells of the fungus $Y 0$ cells showed the presence of both yeast and hyphal forms adhering to the tissues (Fig. 2C).

We compared the effect of $C$. albicans morphotype on its pathogenicity in silkworms by injecting each cell type, Y0, Y60, and H120 cells. The survival rate of those incubated at $30^{\circ} \mathrm{C}$ is shown in Fig. 3A; no apparent differences were observed between the $\mathrm{Y} 0$ cells and $\mathrm{H} 120$ cells. However, Y60 cells showed higher pathogenicity than the other 2 cell types, indicating that a morphological transition from yeast to hyphae, but not of yeast-form or hyphal cells, is involved in the pathogenesis of our silkworm model. We also addressed the question whether mortality of silkworms is associated with the proliferation of $C$. albicans in infected larvae. We counted the CFU from injected silkworms $24 \mathrm{~h}$ post-injection. The groups injected with $1 \times 10^{5} \mathrm{Y} 0$ cells or $\mathrm{H} 120$ cells showed a lower number of CFU than that injected with Y60 cells (Fig. 3B). The group injected with Y60 cells showed a proliferation of $C$. albicans at $24 \mathrm{~h}$ post-injection. These results correlated well 


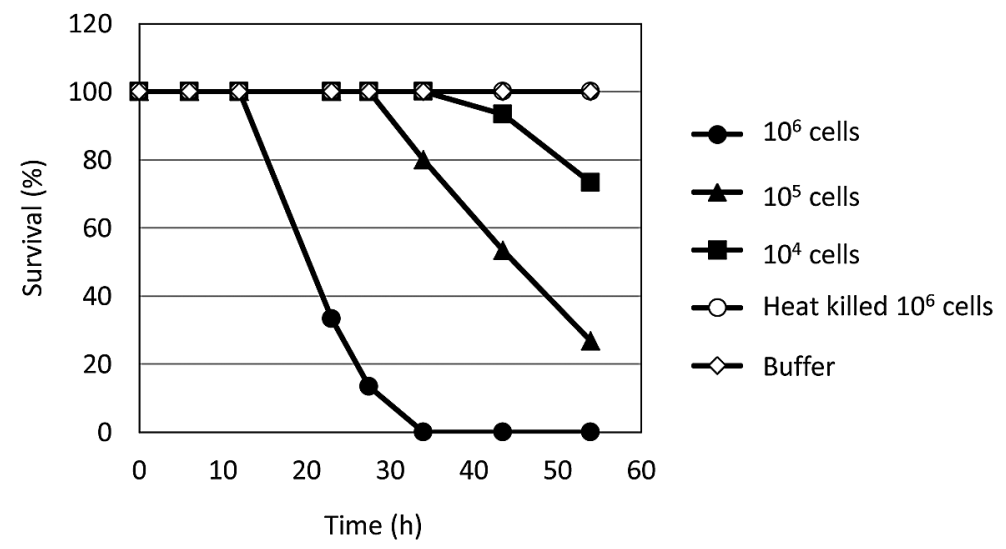

(a)

Oh

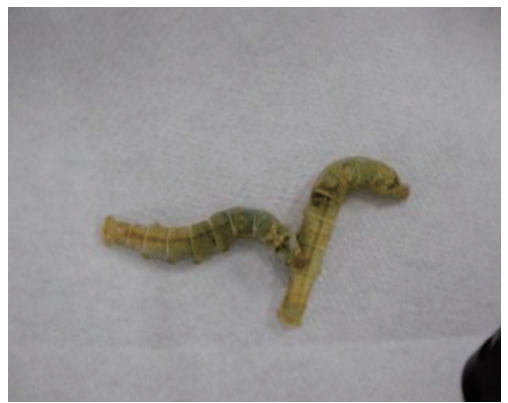

(b)
$48 \mathrm{~h}$

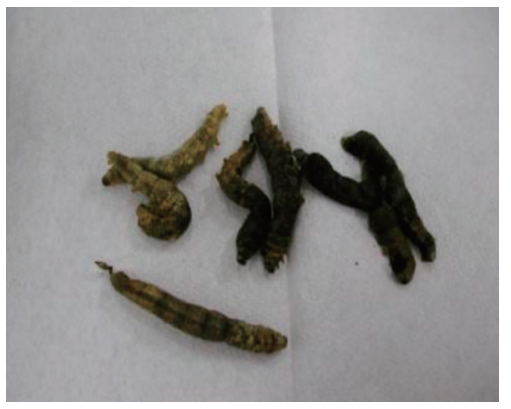

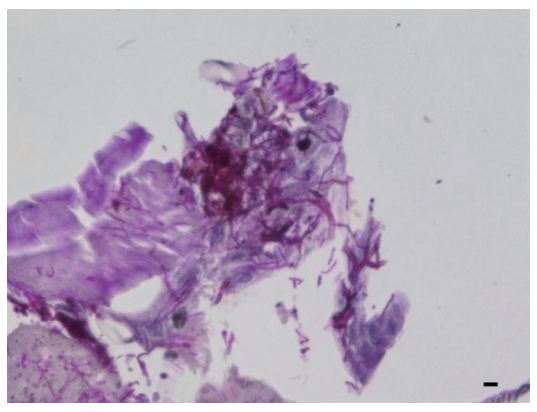

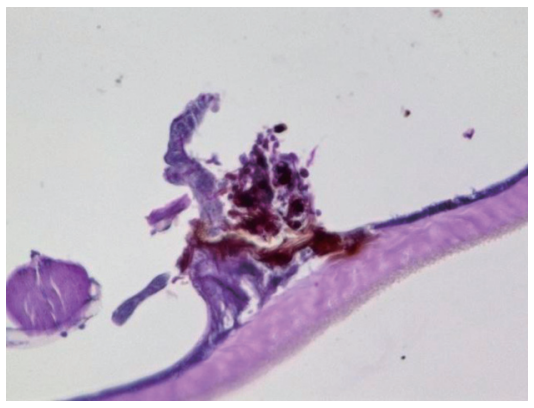

(c)

Fig. 2. (A) Survival rates of larvae infected with Candida albicans Y0 cells. Yeast-form cells at 0 min after incubation in the GlcNAc medium (Y0 cells) were prepared as described in Materials and Methods and then injected into larvae $\left(10^{4}, 10^{5}\right.$, and $10^{6}$ cells/g-silkworm). The silkworms were kept at $30^{\circ} \mathrm{C}$ and those surviving were counted at various time points. C. albicans suspensions in phosphate buffer and heat-treated cells $\left(10^{6}\right.$ cells/gsilkworm) injected into the larvae were used as control. (B) Living larvae before injection (left) and dead larvae at $48 \mathrm{~h}$ post-injection of $C$. albicans $\left(10^{6}\right.$ cells/g-silkworm). (C) PAS staining of fungal cells in silkworm tissues. Y0 cells ( $10^{5}$ cells/g-silkworm) were injected into larvae. Larval tissue sections were obtained $24 \mathrm{~h}$ post-injection and at $30^{\circ} \mathrm{C}$. Bar represents $10 \mu \mathrm{m}$.

with the higher pathogenicity of $\mathrm{Y} 60$ cells. The infection model at $37^{\circ} \mathrm{C}$ enables the study of temperature-related virulence of $C$. albicans, especially when the normal human body temperature is also $37^{\circ} \mathrm{C}$. An advantage of silkworms and G. mellonella over other invertebrate mini-hosts is their survival at $37^{\circ} \mathrm{C}^{10)}$. We also observed a slightly higher pathogenicity using $\mathrm{Y} 60$ cells compared to the other 2 cell types at $37^{\circ} \mathrm{C}$ (Fig. $3 \mathrm{~A}$ ). Comparison of 32-h survival rates between $\mathrm{Y} 0$ and Y 60 cells at $30^{\circ} \mathrm{C}$ and $37^{\circ} \mathrm{C}$ showed a small 1.9 -fold increase in mortality at $37^{\circ} \mathrm{C}(P=0.096)$, whereas a 

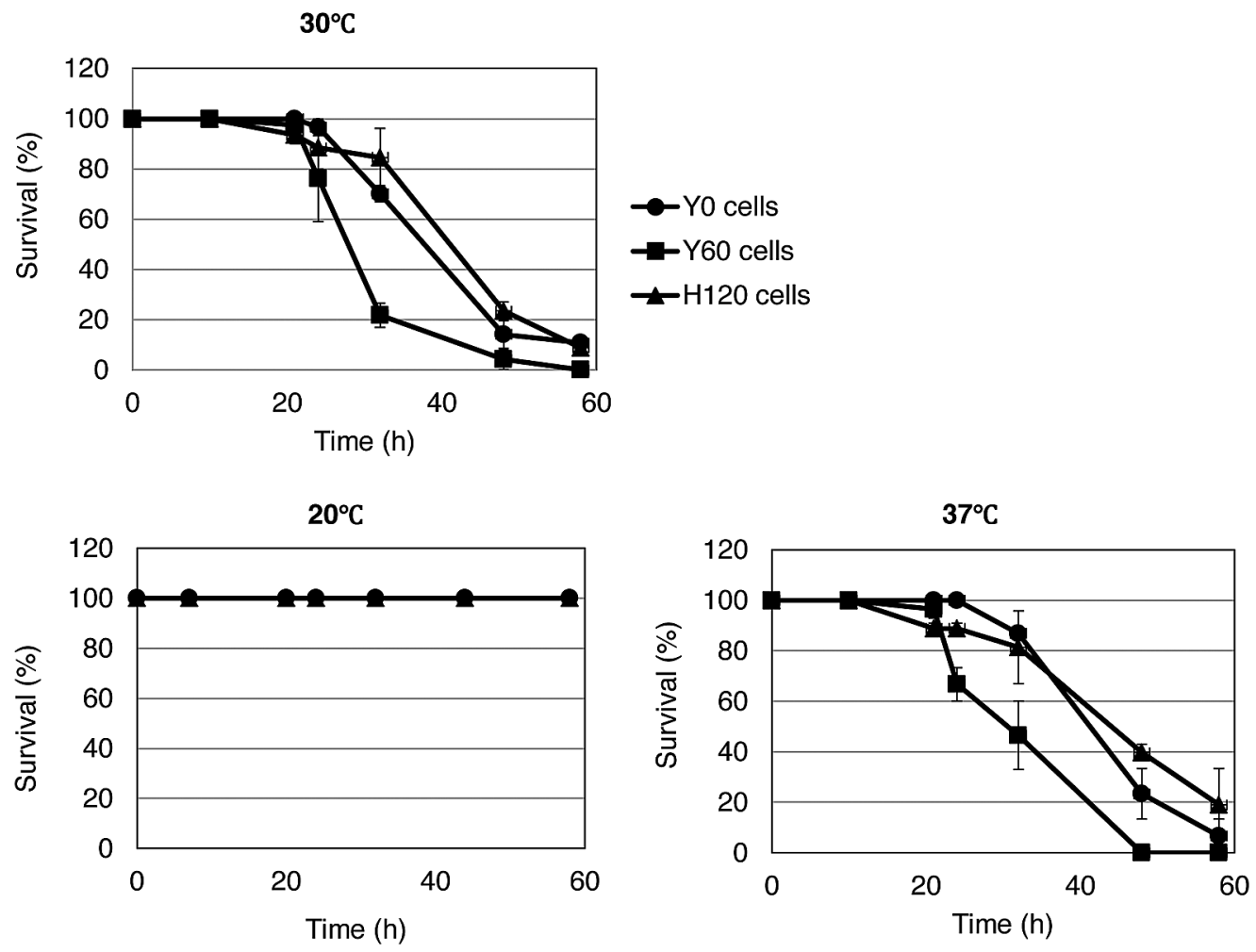

(a)
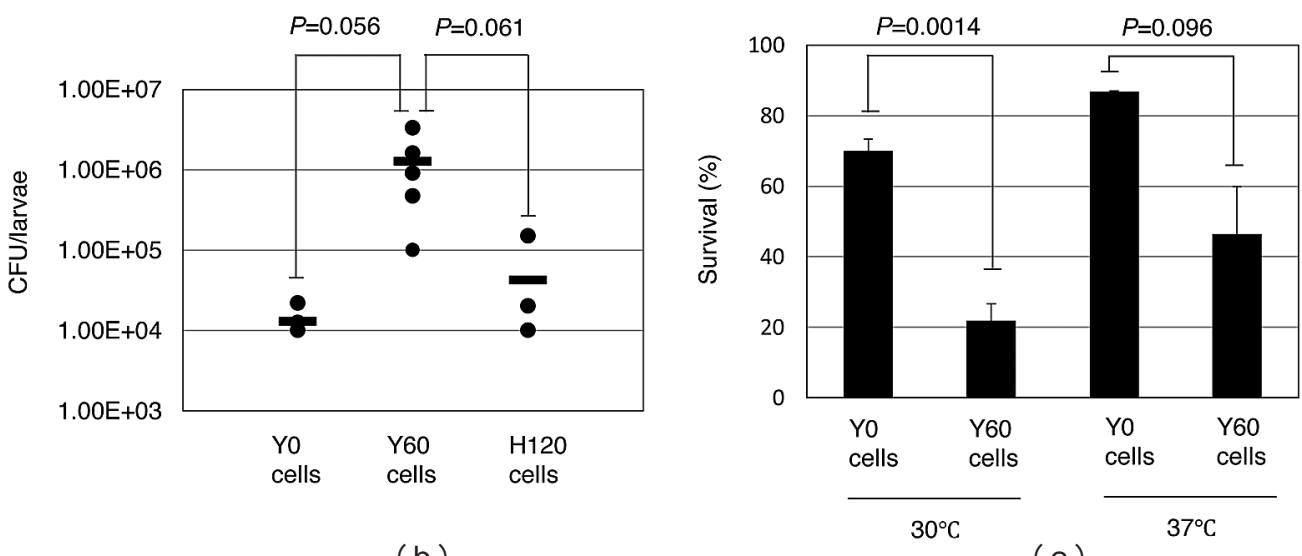

(b)

(c)

Fig. 3. Effect of $C$. albicans morphotype on its pathogenicity in silkworms. Yeast-form cells at 0 min after incubation in the GlcNAc medium ( $Y 0$ cells), yeast-form cells in germination-ready state at $60 \mathrm{~min}$ (Y60 cells), and hyphal cells at $120 \mathrm{~min}$ (H120 cells) were prepared as described in Materials and Methods. (A) Silkworms were injected with each cell type $\left(10^{5} \mathrm{cells} / \mathrm{g}\right.$ silkworm) and incubated at various temperatures, and their survival rates were determined at various time points. (B) Comparison of $C$. albicans burden in silkworms based on cell type. Silkworms $(n=5)$ injected with Y0, Y60, or H120 cells were homogenized $24 \mathrm{~h}$ post-injection. The samples were diluted, plated onto a YPD agar medium, and incubated at $37^{\circ} \mathrm{C}$ for $24 \mathrm{~h}$. Colonies that emerged on the agar plates after $24 \mathrm{~h}$ were counted. Each dot indicates the number of $C$. albicans in 1 silkworm. The horizontal line represents the value of the group. (C) Comparison of survival rates in $\mathrm{Y} 0$ and $\mathrm{Y} 60$ cells $32 \mathrm{~h}$ post-injection at $30^{\circ} \mathrm{C}$ and $37^{\circ} \mathrm{C}$.

significant 3. 2-fold increase $(P=0.0014)$ was observed at $30^{\circ} \mathrm{C}$ (Fig. $3 \mathrm{C}$ ). The infection assay of injecting the 3 types of the cells $\left(10^{5}\right.$ cells) into the larvae at $20^{\circ} \mathrm{C}$ resulted in a $100 \%$ survival rate at 58 $\mathrm{h}$ post-injection (Fig. $3 \mathrm{~A}$ ), similar to the results obtained after injecting heat-inactivated cells or phosphate buffer.

\section{Morphogenesis in hemolymph in vitro}

Inoculation of $C$. albicans in $10 \%$ hemolymph in 
vitro showed that it remained in its yeast form in $\mathrm{Y} 0$ cells after $2 \mathrm{~h}$ of incubation at $30^{\circ} \mathrm{C}$. In contrast, approximately $70 \%$ of the $\mathrm{Y} 60$ cells germinated $2 \mathrm{~h}$ post-injection (Figs. $4 \mathrm{~A}$ and $4 \mathrm{C}$ ). At $37^{\circ} \mathrm{C}$, no differences were observed in either cell type; approximately $90 \%$ of the cells germinated at $2 \mathrm{~h}$ (Figs. 4B and $4 \mathrm{C}$ ), indicating that $\mathrm{Y} 60$ cells have a higher capacity to undergo a morphological transition than $Y 0$ cells at $30^{\circ} \mathrm{C}$. In addition, these results also suggest that silkworm hemolymph may contain hyphal-inducing factors.

\section{Discussion}

Animal models have been used to investigate virulence factors in $C$. albicans applying various research techniques. Mutant strains of $C$. albicans have also been commonly used for infection studies. We developed a new approach for evaluating the pathogenicity of 3 different GlcNAc-induced $C$. albicans cell conditions in a silkworm infection model.

Our results showed that silkworm mortality was dependent on the concentration of injected cells (Fig. 2). Y60 cells proliferated to an average of $10^{6}$ cells CFU in the silkworms and induced higher mortality than the other 2 cell types (Fig. 3), thereby indicating higher pathogeni-city. Y 60 cells showed a yeast form, but its cellular condition was different from that of $Y 0$ cells. Our microarray analysis demonstrated that the GlcNAc medium induced the upregulation of some genes including CAMP-PKA dependent genes by 30-min incubation (Table 1). We propose that at least upregulation of cAMP-PKA dependent genes would be maintained in Y60 cells because Cho et al. ${ }^{24)}$ reported a time-dependent increase of intracellular cAMP level during 180-min incubation in the GlcNAc medium. Therefore, Y60 cells were ready for germination and could transition from yeast to hyphae when cultured in $10 \%$ silkworm hemolymph for $2 \mathrm{~h}$ at $30^{\circ} \mathrm{C}$, whereas $\mathrm{YO}$ cells could not. $\mathrm{H} 120$ cells were hyphal in form but showed the same level of pathogenicity as that observed in $Y 0$ cells, suggesting that the transition from yeast to hyphae, but not the morphotypes of yeast-form and hyphal cells, is involved in $C$. albicans virulence in the silkworm. The morphological switch is a complex transition process involving changes in cellular form and properties, including adhesion and invasion into host cells. We found a marked upregulation of $A L S 3$ by 30 -min incubation in the GlcNAc medium, which facilitates mucosal invasion through the epithelial receptor Ecadherin and is a cAMP-PKA pathway dependent gene ${ }^{25,26)}$. Y60 cells may thus possess higher ability to adhere to the host cells than YO cells. Although $\mathrm{H} 120$ cells in hyphal form should highly express Als3p on the cell surface and thus adhere to the tissues, the cells showed reduced virulence compared to Y60 cells, which supports that the transition from yeast to hyphae is important for $C$. albicans virulence in the silkworm. Silkworm possesses several defense mechanisms in its innate immune system. Hemocytes are responsible for a number of defense responses in insects, including phagocytosis, nodulation, and melanization ${ }^{27)}$. We propose that $Y 60$ cells are capable of undergoing rapid transition from yeast to hyphal form in vivo, thus evading the host's immune responses, and resulting in their proliferation and tissue colonization.

On the basis of the capacity of silkworms to survive at the human physiological temperature of $37^{\circ} \mathrm{C}$, we thus performed an infection study at this temperature (Fig. 3A). We observed a slightly higher pathogenicity of $Y 60$ cells compared to other cell types. However, the difference in mortality between the $Y 0$ and $Y 60$ cells at $32 \mathrm{~h}$ post-injection was less apparent at $37^{\circ} \mathrm{C}$ (Fig. $3 \mathrm{C}$ ). We observed no differences in cell morphology between $\mathrm{Y} 0$ and $\mathrm{Y} 60$ cells cultured in 10\% hemolymph and maintained at $37^{\circ} \mathrm{C}$, with both cells showing the same extent of germination (Fig. 4C). This result may explain no significant difference in mortality rate between the $\mathrm{Y} 0$ and $\mathrm{Y} 60$ cells observed at $37^{\circ} \mathrm{C}$ as shown in Fig. $3 \mathrm{C}$. In addition, these data suggest that other virulence factors may be involved in silkworm infection at $37^{\circ} \mathrm{C}$. We also found a marked upregulation of the genes involved in the GlcNAc metabolism and amino acid biosynthesis by 30-min incubation in the GlcNAc medium (Table 1). However, the virulence of these genes has not yet been clarified and we plan to investigate the role of these genes in silkworm infection in the future.

To date, invertebrate mini-host systems including $D$. melanogaster ${ }^{2,3)}, C$. elegans ${ }^{4,5)}, G$. mellonella $a^{6-8,14)}$ and, more recently, Zebra fish ${ }^{28)}$ have been developed to study the virulence factors of $C$. albicans in epithelial infections. In this study, we used the silkworm model because of its low cost, the association of minimal ethical 

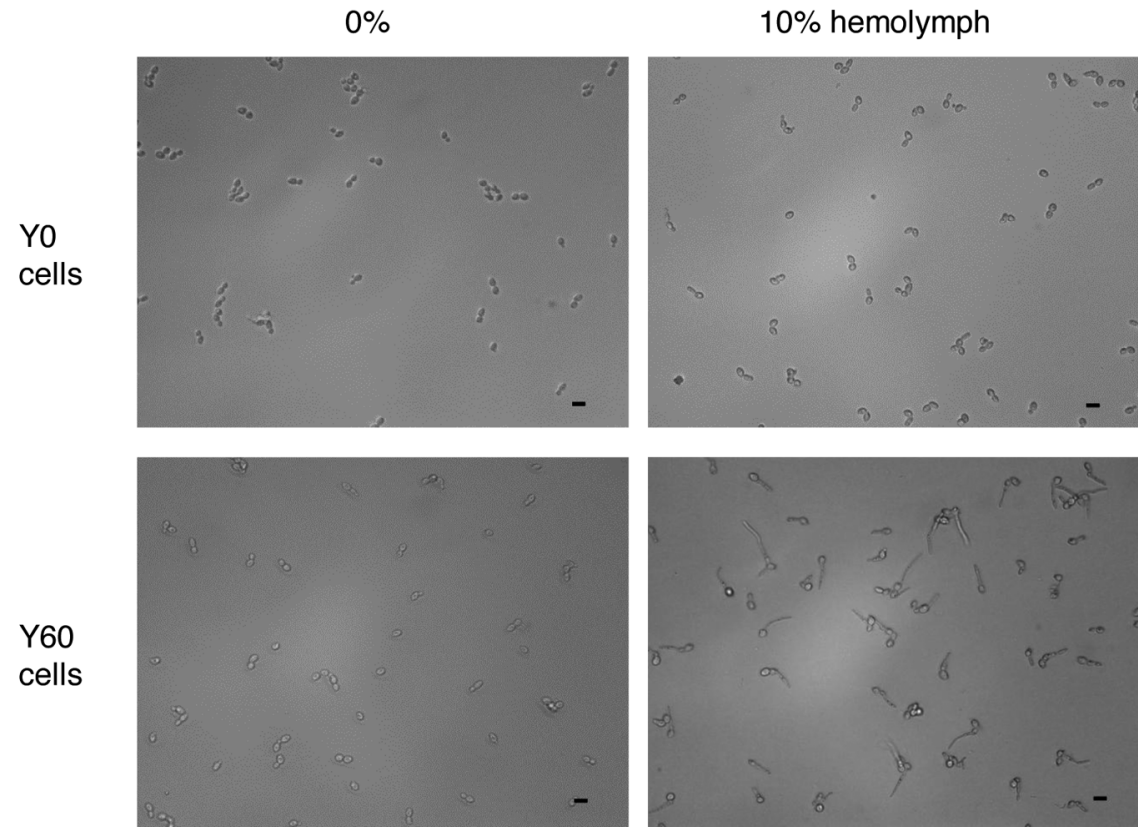

( a )
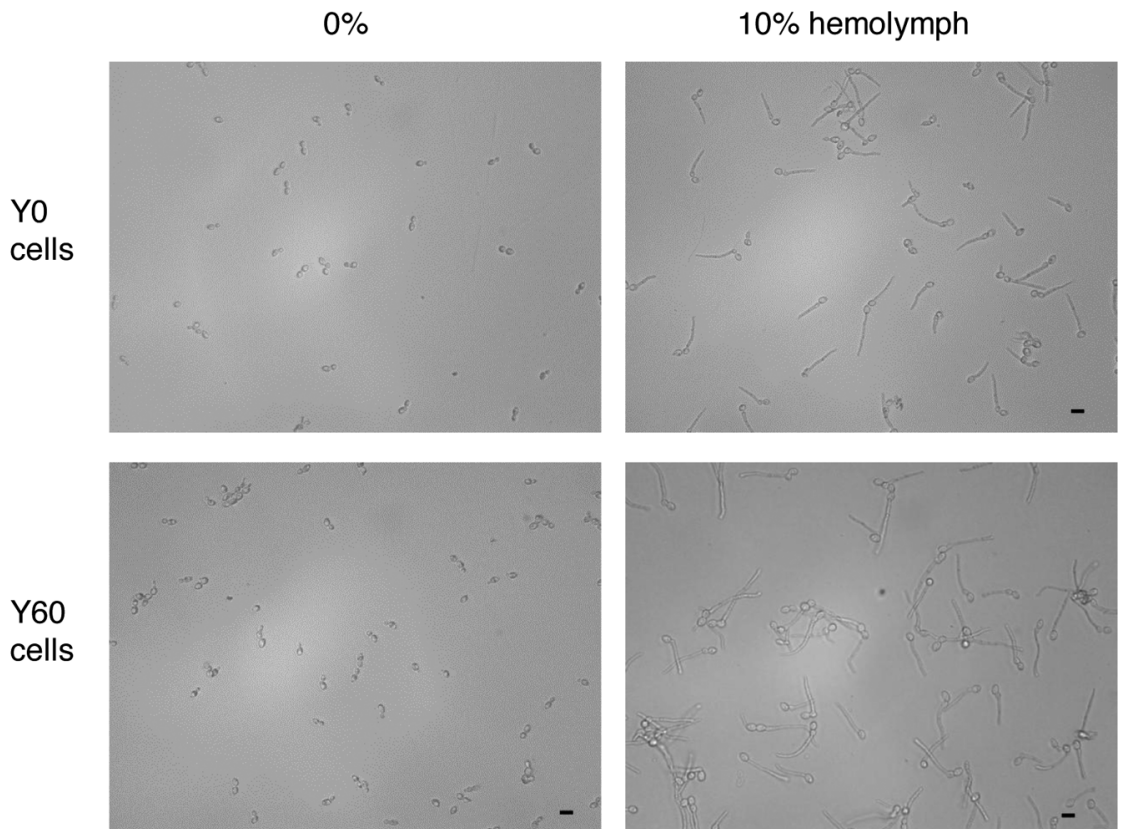

(b)

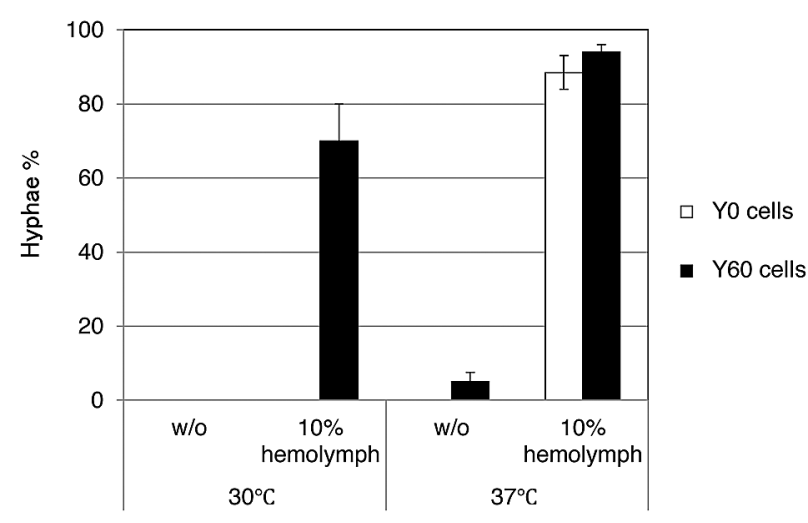

(c)
Fig. 4. Morphogenesis of $C$. albicans in hemolymph cultures. C. albicans $\mathrm{Y} 0$ and $\mathrm{Y} 60$ cells were inoculated in $10 \%$ germ-free hemolymph for $2 \mathrm{~h}$ at $30^{\circ} \mathrm{C}(\mathrm{A})$ or $37^{\circ} \mathrm{C}$ (B). The morphology of the cells was determined by microscopic examination. Bar represents $10 \mu \mathrm{m}$. (C) The percentage of hyphal cells was determined by observing 200 cells. 
Table 1. Genes upregulated by incubation in the GlcNAc medium ${ }^{2}$

\begin{tabular}{|c|c|c|c|}
\hline Category & Gene & Function & Fold change \\
\hline \multirow[t]{4}{*}{ GlcNAc utilization } & NAG1 & Glucosamine-6-phosphate deaminase & 83.8 \\
\hline & $D A C 1$ & GlcNAcN-6-phosphate deacetylase & 76 \\
\hline & NGT1 & GlcNAc-specific transporter & 66.9 \\
\hline & HXK1 & GlcNAc kinase & 33.8 \\
\hline \multirow[t]{5}{*}{$\begin{array}{l}\text { Amino acid } \\
\text { biosynthesis/permease }\end{array}$} & ILV5 & Valine biosynthesis & 4 \\
\hline & AR08 & Aromatic amino acid aminotransferase & 4.6 \\
\hline & LYS2 & Lysin biosynthesis & 4.4 \\
\hline & ARG1 & Arginine biosynthesis & 22.1 \\
\hline & GAP1 & Amino acid permease & 13.2 \\
\hline \multirow[t]{3}{*}{ Carbon metabolism } & CIT1 & Citrate synthase & 2 \\
\hline & FAA23 & Fatty acyl-CoA synthetase & 6.3 \\
\hline & FBP 1 & Fructose-1,6-bisphosphatase & 4.3 \\
\hline \multirow[t]{6}{*}{ Others } & ALS3 & Hypha specific ALS family cell wall adhesin & 23.6 \\
\hline & FRP1 & Ferric reductase & 4 \\
\hline & HSP12 & Heat-shock protein & 4.6 \\
\hline & $D Q D 1$ & Putative 3-dehydroquinate dehydratase & 4.7 \\
\hline & IPF4119.5 & Unknown function & 4.7 \\
\hline & IPF6617.repeat1 & Unknown function & 3.7 \\
\hline
\end{tabular}

a. Genes upregulating more than 2-fold relative to that of logarithmic phase cells before

issues, and its ease of manipulation. Our findings suggested that the yeast to hyphal transition induced by the GlcNAc medium contributed to the virulence of $C$. albicans in the silkworm. Our findings provide a convenient approach to investigating the relationship between pathogenicity and morphological events in C. albicans. To validate the experimental approach and findings in this study, a mouse/rat mucosal infection model will be utilized in our future research studies.

\section{Acknowledgments}

The authors are grateful to Dr. Rieko Imayoshi of Fukuoka Dental College for supporting the infection experiments in this study. This work was also supported by a Grant-in-Aid for Young Scientists (Start-up) from the Japan Society for the Promotion of Science (Grant no. 20890274), by a Grant-in-Aid for strategic study base formation support business (S1001059), and by the Kato Memorial Bioscience Foundation.

\section{References}

1) Pfaller MA, Messer SA, Hollis RJ, Jones RN, Diekema DJ: In vitro activities of ravuconazole and voriconazole compared with those of four approved systemic antifungal agents against 6,970 clinical isolates of Candida spp. Antimicrob Agents Chemother 46: 1723-1727, 2002.

2) Kounatidis I, Ligoxygakis $P$ : Drosophila as a model system to unravel the layers of innate immunity to infection. Open Biol 2: 120075, 2012.

3) Chamilos G, Lionakis MS, Lewis RE, Lopez-Ribot JL, Saville SP, Albert ND, et al: Drosophila melanogaster as a facile model for large-scale studies of virulence mechanisms and antifungal drug efficacy in Candida species. J Infect Dis 193: 1014-1022, 2006.

4) Pukkila-Worley R, Peleg AY, Tampakakis E, Mylonakis E: Candida albicans hyphal formation and virulence assessed using a Caenorhabditis elegans infection model. Eukaryot Cell 8: 1750-1758, 2009.

5) Pukkila-Worley R, Ausubel FM, Mylonakis E: Candida albicans infection of Caenorhabditis elegans induces antifungal immune defenses. PLoS Pathog 7: e1002074, 2011.

6) Fallon J, Kelly J, Kavanagh K: Galleria mellonella as a model for fungal pathogenicity testing. Methods Mol Biol 845: 469-485, 2012.

7) Fuchs BB, O'Brien E, Khoury JB, Mylonakis E: Methods for using Galleria mellonella as a model host to study fungal pathogenesis. Virulence 1 : 475-482, 2010.

8) Brennan M, Thomas DY, Whiteway M, Kavanagh K: Correlation between virulence of Candida albi- 
cans mutants in mice and Galleria mellonella larvae. FEMS Immunol Med Microbiol 34: 153-157, 2002.

9) Junqueira JC: Models hosts for the study of oral candidiasis. Adv Exp Med Biol 710: 95.105, 2012.

10) Chamilos G, Lionakis MS, Lewis RE, Kontoyiannis DP: Role of mini-host models in the study of medically important fungi. Lancet Infect Dis 7 : 42-55, 2007.

11) Sudbery P, Gow N, Berman J: The distinct morphogenic states of Candida albicans. Trends Microbiol 12: 317-324, 2004.

12) Kadosh D, Johnson AD: Induction of the Candida albicans filamentous growth program by relief of transcriptional repression: a genome-wide analysis. Mol Biol Cell 16: 2903-2912, 2005.

13) Whiteway $M$, Bachewich $C$ : Morphogenesis in Candida albicans. Annu Rev Microbiol 61: 529-553, 2007.

14) Fuchs BB, Eby J, Nobile CJ, El Khoury JB, Mitchell AP, Mylonakis E: Role of filamentation in Galleria mellonella killing by Candida albicans. Microbes Infect 12: 488-496, 2010.

15) Hamamoto H, Kurokawa K, Kaito C, Kamura K, Manitra Razanajatovo I, Kusuhara $\mathrm{H}$, et al: Quantitative evaluation of the therapeutic effects of antibiotics using silkworms infected with human pathogenic microorganisms. Antimicrob Agents Chemother 48: 774-779, 2004.

16) Hanaoka N, Takano $Y$, Shibuya K, Fugo H, Uehara $Y$, Niimi M: Identification of the putative protein phosphatase gene PTC1 as a virulence-related gene using a silkworm model of Candida albicans infection. Eukaryot Cell 7: 1640-1648, 2008.

17) Lay J, Henry LK, Clifford J, Koltin Y, Bulawa CE, Becker JM: Altered expression of selectable marker URA3 in gene-disrupted Candida albicans strains complicates interpretation of virulence studies. Infect Immun 66: 5301-5306, 1998.

18) Brand A, MacCallum DM, Brown AJ, Gow NA, Odds FC: Ectopic expression of URA3 can influence the virulence phenotypes and proteome of Candida albicans but can be overcome by targeted reintegration of URA3 at the RPS10 locus. Eukaryot Cell 3: 900-909, 2004.
19) Cheng S, Nguyen MH, Zhang Z, Jia H, Handfield M, Clancy CJ: Evaluation of the roles of four Candida albicans genes in virulence by using gene disruption strains that express URA3 from the native locus. Infect Immun 71: 6101-6103, 2003.

20) Sundstrom P, Cutler JE, Staab JF: Reevaluation of the role of HWP1 in systemic candidiasis by use of Candida albicans strains with selectable marker URA3 targeted to the ENO1 locus. Infect Immun 70: 3281-3283, 2002.

21) Chen $X$, Magee BB, Dawson $D$, Magee $P T$, Kumamoto CA: Chromosome 1 trisomy compromises the virulence of Candida albicans. Mol Microbiol 51: 551-565, 2004.

22) Cho $T$, Hamatake $H$, Kaminishi $H$, Hagihara $Y$, Watanabe K: The relationship between cyclic adenosine 3', 5'-monophosphate and morphology in exponential phase Candida albicans. J Med Vet Mycol 30: 35-42, 1992.

23) Kaito $C$, Akimitsu $N$, Watanabe $H$, Sekimizu $K$ : Silkworm larvae as an animal model of bacterial infection pathogenic to humans. Microb Pathog 32: 183-190, 2002.

24) Cho $T$, Aoyama $T$, Toyoda $M$, Nakayama $H$, Chibana $\mathrm{H}$, Kaminishi $\mathrm{H}$ : Transcriptional changes in Candida albicans genes by both farnesol and high cell density at an early stage of morphogenesis in N-acetyl-D-glucosamine medium. Med Mycol J 48: 159-167, 2007.

25) Bahn YS, Molenda M, Staab JF, Lyman CA, Gordon LJ, Sundstrom P: Genome-wide transcriptional profiling of the cyclic AMP-dependent signaling pathway during morphogenic transitions of Candida albicans. Eukaryot Cell 6: 2376-2390, 2007.

26) Hoyer LL, Green CB, Oh SH, Zhao X: Discovering the secrets of the Candida albicans agglutininlike sequence $(A L S)$ gene family--a sticky pursuit. Med Mycol 46: 1-15, 2008.

27) Marmaras VJ, Lampropoulou M: Regulators and signalling in insect haemocyte immunity. Cell Signal 21: 186-195, 2009.

28) Chao CC, Hsu PC, Jen CF, Chen IH, Wang CH, Chan $\mathrm{HC}$, et al: Zebrafish as a model host for Candida albicans infection. Infect Immun 78: 2512-2521, 2010. 